\title{
Exposure Total Volume Administration
}

National Cancer Institute

\section{Source}

National Cancer Institute. Exposure Total Volume Administration. NCI Thesaurus. Code C83163.

The gross volume of the apportioned exposure. 